\title{
Schooling: Knowledge, Perception and Practices of Parents
}

Saraswoti Bharati and Hosokawa Takao*

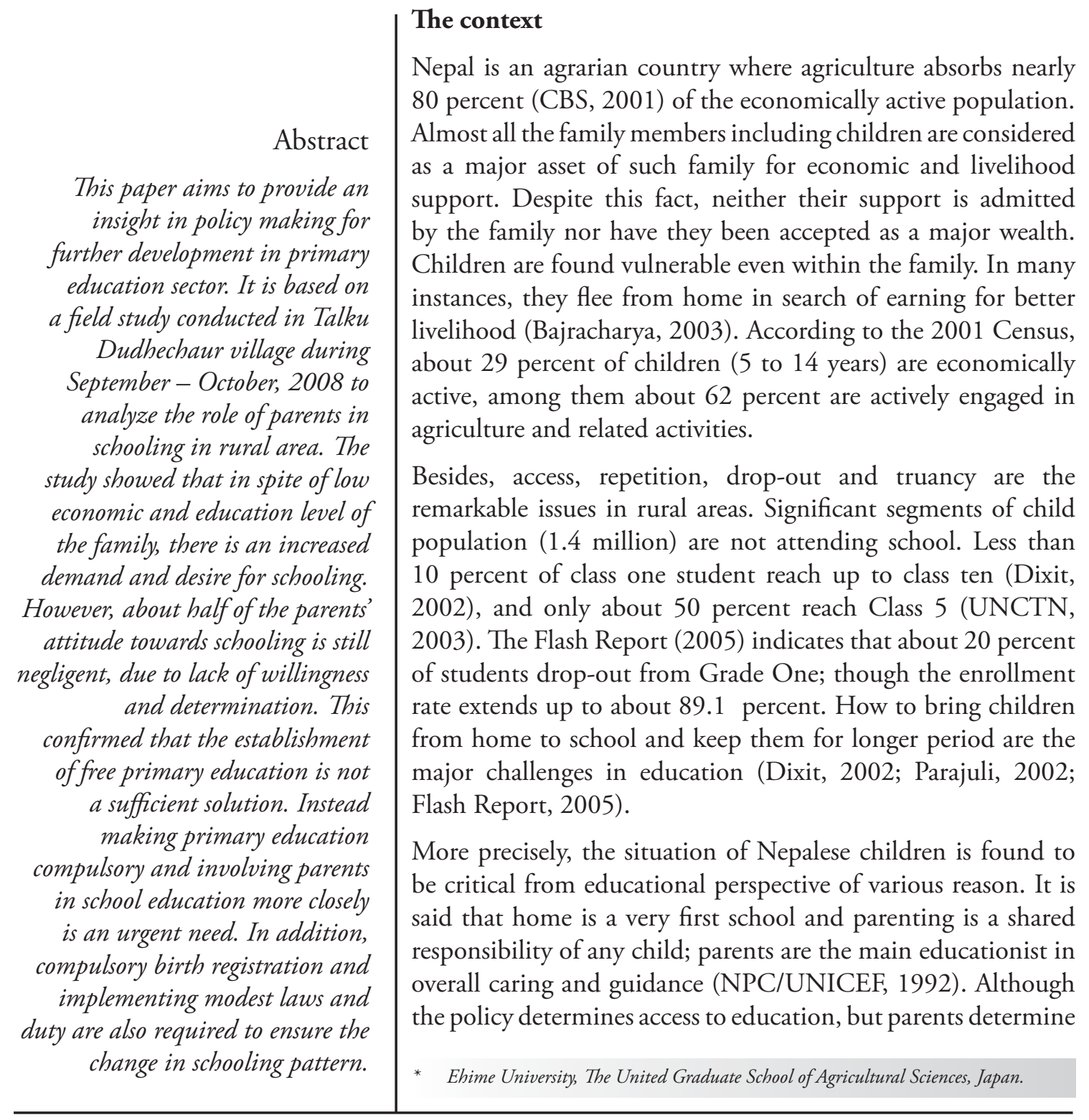

Journal of Education and Research Vol. 2, 2010 
Schooling: Knowledge, Perception and Practices of Parents $\mid$

whether or not children actually enroll in school (Dhital et al., nd.).

It is reasonable to surmise that the issue remains hidden in Nepalese research. It could be that concerned professionals are intensive to the economic and political factors rather than social one. If the social issue rises; it is always limited within gender, ethnicity and minority. Important member of such society 'parents' are never considered as a factor due to social belief that "none of the parent thought the evil of own child". It is true, but knowingly and unknowingly the way parental decision affects a lot starts from the days of womb and continues throughout life. Thus, the main objective of this paper is based on one determining factor 'parents' as a case; first to know the parental knowledge and perception about schooling and second, to analyze their participation and practices in school education. The study is based basically on these questions - Is parents' 'decision' crucial in schooling? Are parents aware of their own decision which is crucial for the whole life and the livelihood of their children? If children are enrolled, in what way are parents participating and supporting in school education. This paper is seeking answers to these questions to fulfill the above mentioned objectives.

\section{The method}

The questionnaire was tested in 'Kami Gaun'" of Lalitpur district, in July-August 2007. Twenty four households of scheduled caste group 'Kami' were selected for this purpose. Later Talku Dudechaur village of Kathmandu district was selected fot this study. Among 547 households, children below the age of 14 from 206 households were selected purposively. The empirical data of household were collected from semi - structural questionnaire in September-October, 2008. Series of informal discussions with schools head teachers and concerned teachers through sharing their personal experiences were recorded. The focus group discussions with grade four and five children were done; this information was later linked to regularity, and truancy.

\section{Findings and discussion}

Schooling is a means to reduce poverty, inequality, empowering children (UNESCO, 2004). This knowledge of schooling in sampled village was found similar: parents considered school as a learning institution confined within the structure of four walls and a roof, a common learning place for better future to serve the society they belong to. Schooling for them is to flourish the dream of sundar vabishya (bright future), sukhijiwon (better life) and sabai kura ramro (better in everything). Schooling of its very nature for better in every aspect is directly related to economic benefits. The "better" knowledge focuses as a productive power which involves in the epistemological decentering of the subject (Thomas, 1986). Decentering of the subject can be taken in two approaches, first the constructive approaches that construct the child of having a childhood and access to opportunities, whereas the discursive practices through which parents become a calculable objects of scrutiny and reflection (Popkewitz and Brennan, 1998). Taking parents of Talku, this ideological knowledge focuses school as 'a commercial bank'; where future job is to be deposited. Teachers are the bankers to generate knowledge for better future.

The "hidden ideology" of such knowledge made by parents towards schooling is explored as "something" that articulates social interest and forces to schooling for urban modern life; rather as a productive practice in the construction of power for own self. Thus the knowledge of schooling is "something" that is invisible of betterment for white neck, table work, and good job linked with 'sukha' (prosperous life) in their terms. Especially this sukha is not expected in any laborious hard work of agrarian life. The knowledge is directly linked to their expectation for unknown "better" of tomorrow unfastened to rural life. This indicates parents are fully aware of education. 
Table - 1 : Education and Secondary occupation's inter- relation within the sampled household

\begin{tabular}{|c|c|c|c|c|c|c|c|}
\hline \multirow[b]{2}{*}{$\begin{array}{c}\text { Education level } \\
\text { (no.) }\end{array}$} & \multicolumn{7}{|c|}{ Occupation ( secondary) } \\
\hline & $\begin{array}{l}\text { Agri- } \\
\text { culture }\end{array}$ & Business & $\begin{array}{l}\text { Daily } \\
\text { wage } \\
\text { labor }\end{array}$ & $\begin{array}{c}\text { Govern- } \\
\text { ment } \\
\text { worker }\end{array}$ & $\begin{array}{l}\text { Firewood } \\
\text { collection/ } \\
\text { sell }\end{array}$ & $\begin{array}{l}\text { Technical } \\
\text { worker }\end{array}$ & $\begin{array}{l}\text { Pension/ } \\
\text { support }\end{array}$ \\
\hline Illiterate (95) & 18 & 6 & 47 & 3 & 9 & 11 & 1 \\
\hline Literate (56) & 14 & 5 & 18 & 2 & - & 10 & 7 \\
\hline Primary (33) & 9 & 1 & 11 & 4 & - & 8 & \\
\hline $\begin{array}{l}\text { Lower secondary } \\
\text { (11) }\end{array}$ & 2 & 1 & 6 & 1 & - & 1 & - \\
\hline Secondary (4) & 1 & - & 1 & 1 & -1 & 1 & - \\
\hline $\begin{array}{l}\text { Above secondary } \\
\text { (1) }\end{array}$ & - & - & - & 1 & - & - & - \\
\hline Total (200) & 44 & 13 & 83 & 12 & 9 & 31 & 8 \\
\hline
\end{tabular}

Source: Field survey, 2008

The expectation of parents for schooling undoubtedly builds an important foundation for access to schooling of any children. However, viewing the perceptional ideology; taking parents of Talku village two different streams of perceptions found - (1) the experiential stream and (2) the problematic stream. The first resembles the positive and negative experiences of parents, where different experience of the self forces to think about school and schooling for children. The stereotyped perception that formal schooling is lack of visible benefits to agriculture (Prennushi, 1998) and that education is the financial consumption rather than investment (Barclay et al. 1996) was not found. Conversely, the difference in positive and negative experiences of parents enabled to perceive - education as a gate way for better life and everyday living. The data on economic analysis of the family income shows economically too poor parents are even willing to send their children comparing to those of having some economic sources (Bharati, 2009a).

At the other extreme, the second stream is of less interested, problematising own problem and practices. The psychology of 'we are poor' and this poorness linked to 'dukha' (hard life). This psychological perception of 'we are poor' and 'dukha' have been transferred from generations. In their views, schooling without secondary level is not workable in the society and it is only suitable for 'rich' people. The richness is linked to schooling and vice versa. This group of parents were found wiling to dependent more on others even though they are not economically weak. It is realized that perception of being poor is deeply rooted in the society for searching easy way rather the true economic fact in the sampled village. Basically, with the name of "dukha" more willingness to get support from external sources was found prominent. The searching of such easy way invites other community members as well, shaking hands and making a bond of dependent culture is getting stronger. This form of increasing dependency is mental poverty rather not economic. They were found familiar with the way of decision they made for schooling and its impact to the future of the children. To conclude, some of the parents were manipulating the fate of the children in the name of dukha.

Finally, analyzing the practices towards schooling, the positive drives for subsequently educational attainment demand are increasing for schooling due to past experience of parents. It is found that 82 percent of parents are now sending their children to school. This percent (82) is 
Schooling: Knowledge, Perception and Practices of Parents $\mid 47$

comparably lower to that of governmental record 87.5 percent (DEO, 2005). It is well established that more educated parents are more likely to send their children to school (Barclay, 1996). But, in the sampled village, even illiterate parents were found more eager to get education to their children. More than half of household heads were uneducated and only four of them had completed secondary education. Even in such educational background, the passion for schooling was found impressive. In contrast to their economic strength and social hierarchy (none of them are in permanent jobs; their income ranges from very minimum to minimum standard level) parents were found to be sending children to schools (Table 1). The desire for schooling was found to be increased for those of experiential stream comparing to the parents of problematic streams. Thus, economic and educational background has very little influences in primary school education rather than parental will and determination.

Nevertheless, the stereotyped philosophy towards female (mother) was found changing in the sample village. It is said that, Nepalese society resembles a patriarchal society, where mother does not have a say in financial activities. They have recessive role in decision making activities. In contrast, the data on decision making while sending children for schooling is interesting: father's decision accounted for 15 percent, mothers decided overall on 5 percent, both (father and mother) combined decision was found to be 80 percent. Family decision on mutual understanding means increment in the trends of 'have a say' of mothers. As experienced by the villagers, this trend is frequently changing for the last 10-15 years. It could be the reason of changing pattern of family structure from joint family to nuclear one, where 98 percent of the informants were of nuclear family. This is another positive aspect of changes in social trend from gender perspective. In spite ofthis, it is still difficult to say that each and every family in Nepal is in transition in practicing the mutual decision making' procedure.
Mother's involvement for schooling was found more compelling than of the fathers without gender disparity. Even uneducated mothers are willing to send their children without bias in gender. Though, elderly children were found biased in some cases (Bharati, 2009b). It is hard to generalize that school access has been increased and gender disparity been reduced due to mother's involvement in decision making. Some data suggest that literacy programmes for uneducated mothers eventually help to increase the number of children in schooling. Studies from Egypt, Ghana, India, Kenya, Malaysia, Mexico, and Peru have found that mothers with basic education are substantially more likely to educate their children, especially their daughters (Levy, 1996; King \& Bellew, 1991; Lillard \& Willis, 1994; Alderman \& King, 1998; Kambhapati \& Pal, 2001; Parker \& Pederzini, 2000; Bhalla, Saigal, \& Basu, 2003). Comparing it, the findings on Nepal are impressive where even the illiterate mother has important influence on schooling of children. The exposure to media, opportunities to mix with outer societies with the advancement of transportation facilities could be reasons of remarkable changes in mother's perception. The changing trend in society definitely affects the educational attainment and achievement of school children, since house hold chores and lack of the family supports are the barriers to education (IMF, 2003). If the practice is continued by parents, then major obstacles will be reduced somehow.

In essence, based on the practices of schooling - four different types of parents were found in the village (Table 2$)$. The $\mathrm{A}$ ( 30 percent) and $\mathrm{B}$ (20 percent) types of parents were found curious about education, willing to pay their attention and taking responsibilities. The metaphorical expression such as -'kalo akshar bhaisi barabar' (no difference in a black buffalo and black letter in their life), 'I com B com, SLC lai dui kam' (no formal schooling) is an example expressed by most parents. They are not willing to face the same problem they had experienced due to lack 
48 Saraswoti Bharati and Hosokawa Takao

Table 2: Parental type and their involvement pattern in schooling by school attendances

\begin{tabular}{|c|c|c|}
\hline $\begin{array}{c}\text { Type of parent } \\
\text { / Percentage }\end{array}$ & $\begin{array}{l}\text { Percentage } \\
\text { of School } \\
\text { Attendance } \%\end{array}$ & Details \\
\hline $\mathrm{A}-30 \%$ & $85-90 \%$ & $\begin{array}{l}\text { Keep concern about school, drop and pick up children to and } \\
\text { from the school by some elders, check school activities, try } \\
\text { to provide time, frequently make queries with the concerned } \\
\text { teacher about their child's performance, less asked for } \\
\text { household chores. }\end{array}$ \\
\hline$B-20 \%$ & $60-65 \%$ & $\begin{array}{l}\text { Visit school for report card collection, try to provide time to } \\
\text { complete homework, rarely asked for assistance, and provide } \\
\text { stationery and other assistances if necessary. }\end{array}$ \\
\hline$C-35 \%$ & $40-45 \%$ & $\begin{array}{l}\text { Due to illiteracy( their own word), do not understand what } \\
\text { children are doing so leave on their own, rarely asked for } \\
\text { assistance }\end{array}$ \\
\hline $\mathrm{D}-15 \%$ & Below $30 \%$ & $\begin{array}{l}\text { Sending children to school to make relief, don't pay any interest } \\
\text { in children activities, as much children spend time outside felt } \\
\text { ease to handle house hold chores, but ask for assistance most } \\
\text { of the time, found work division in some cases. }\end{array}$ \\
\hline
\end{tabular}

Source: Field survey, 2008

of education. Families even with very limited budgets are sending children to school with the expectation that schooling will fascinate them for bright future. Here, 'the same problem like own' represents inabilty to tackle the fast modernization and the way to get out of poverty; so they are comparing own life with the buffalo that considered as dirt, in comparison to holy cow of Hindu culture. It means they regret their life without schooling for various reasons. The gradual demand of schooling in rural areas is a symbol that parents are more convinced with the benefits of education for their children.

Adversly, the $\mathrm{C}$ type (35 percent) were found less curious. Those parents have been sending their children for schooling to convince that their responsibility has been fulfilled. They assume that their responsibility has been transferred to the concerned teachers and school. In their views, the teacher is a 'sole expert' in educating children. This type, due to being illiterate, was found their helpless and unable to know and comment on school related matters.

The $\mathrm{D}$ type (15 percent) found careless in their activities towards schooling and taking the responsibilities (Table 2; Case 1 and 2), children lack voices in parental one way decision. It indicates that even though the knowledge and perception of parents was found positive towards schooling; they are far behind in practice. About half of the society $(C-35$ percent, $D-15$ percent) resembles the problematic type; less careful, lacking of willingness and determination for schooling. So, it is important to focus for those parents to increase the participation in schooling matters.

In response to the regularity practices, parent's day to day decisions were found to have direct relation with the children's education. According to teachers and head teachers, absenteeism seems to be a common phenomenon in school. Children were absent even for simple reason and in some cases they found playing outside the school ground. Sometimes even a wedding in the village affects in their regularity. For the reason, they blame parents, saying that parents simply used to say 'You can leave school today' without proper reason, and sometimes make them busy 
Schooling: Knowledge, Perception and Practices of Parents 49

for simple household chores. They added, even for one day local festival, children do not come to school for 3-4 days. In their views, parents are not favoring and encouraging children for better schooling. Sometimes it seems that these parents are just pretending that they are providing education to their children. Parents can support a lot for regularity, continuation and completion if they wish. Here, the wish symbolizes a willingness of parents. If the fact is compared to above C and $\mathrm{D}$ type of parents, then teachers are found true in some instances. Economy was not the major reason found for schooling children in such families.

The same queries were put to fourth and fifth graders. In response to focus group discussion, children pointed out that parents are responsible for irregularities. 'Parents ask them to come a bit earlier or go late than the usual school time'. Moreover, parents pay less interest in homework and ask for support for household works. In between this blaming culture and the above findings show that parents seem more responsible for their children's better education. Parental

Case 1 (Milan Balami, 12): My sister ran way when she was 14. Parents conducted a formal marriage again taking loan (Rs.10, 000) from village cooperatives for the shake of prestige. After that I'm forced to leave school (grade 3) before 2 years. They said, once they cleared this loan then I can go to school. Now I do cooking, cleaning and feeding the cow in the afternoon, rest of the time I have nothing to do. (Field survey, 2008)

Case2: Laxmi 12 (grade 3) and Bunu 9 (yet to school) are living with grand parents. Once father get married with another lady, they were brought to grand parents place by her mother. Later mother also get married (third time) with another person and left the village. Laxmi is from first husband and Bunu is from the second. (Field survey, 2008) decision from first day of schooling to regularity and continuation has major role in schooling.

If the issues are analyzed from different perspectives, there are very less spaces for parents to be directly involved in school system. The data showed that parents usually visit school - when they are invited to listen to complaints, for the last warning of paying bills, report card collection, and admission. They are asked to meet the accountant during their school visits rather class teacher. Only few interaction programs have been found taking place between school management committee and the school but all parents do not have chances of participation. Even the parents who want to be involved have fear - worried about the forthcoming teacher's negative reactions towards children if they complained. Above all, they lack experiences of schooling. This could be the result that parents do not know the pain of children, stopping their children for minor household chores, delayed schooling and asking for returning home early. This shows that parents are not taking schooling seriously, though they are aware of it. There is a need of space for parents to directly participate in schooling and taste the school culture to decrease the problems faced by children.

The result confirmed that, about half of the parents are fully supporting in schooling where as rest half were found less interested and less supportive, even though they are aware of sending children to school. This decisiveness of parents has a major role in access, truancy, and drop-out. Since, there are rare opportunities for parents to be directly involved in school education system, the awareness cannot be materialized into practices. To overcome the problems, parental involvement in school culture is necessary. The exchange of information with concerned parents is an urgent need for access, continuation and completion of primary schooling.

\section{Conclusions}

The overall data of the village shows that the 
$50 \mid$ Saraswoti Bharati and Hosokawa Takao

low level of the will of the concerned parents is a major drawback for providing schooling to children. Due to lesser interest, will and interaction there is a huge gap in knowledge, perception and practices. This directly affects schooling of children and their future. Bringing changes in parental attitude towards schooling is important. Parents are being alienated from school culture for two reasons - one is their own lack of experience and due to being alienated by the system taken as an unaware (illiterate) member of the society and have fewer chances to get involved in school culture. Until and unless parents are not actively involved in school activities from the starting period of schooling, there will always remain a huge gap in school and home culture. These cultures are more prominent and continue in parental decisions for schooling affecting the future of children in rural areas. In a country like ours, where there is no compulsory education and no rule for those parents, who do not send their children to school, parents participation and involvement can work as a driving force for compulsory to education

\section{References}

Alderman, H. \& King, E. M. (1998). Gender differences in parental investment in education. Structural Change and Economic Dynamics, 9(4), 453-468.

Bajracharya, H. R. (2003). Education for Poverty Reduction: the Challenges of School Reforms. Education and Development. Kathmandu: Research Center for Educational Innovation and Development.

Barclay, K. \& Boone, E. (1996). Inviting Parents to Join in the Educational Process: What Research tells us about Parent Involvement. Community Education Journal, 24, 16-18.

Bharati, S. (2009a). Education and Development in Nepal A case study on Talku village. Paper presentated at International
Conference, Tomorrow People, Thailand 2009, 249 - 263.

(2009b). Effect of Educational Values and Cultural Tradition in Access to School. The International Journal of Learning, 16(9), 611 - 620.

Central Bureau of Statistics. (2004). Nepal Living Standards Survey, 1996. Kathmandu: National Planning Commission.

Dhital, P., Thomsan, J. S., \& Flanagan C.A. (na). Extra parental education and educational participation of primary school age children in Chitwan, Nepal. Association for International Agricultural and Extension Education. http://www.aiaee. org

Dixit, S. (2002). "Education, deception, state and society”. Kathmandu.

Ministry of Education and Sports. (2005). Flash Report I. Kathmandu: Author.

HMG/UNCTN. (2003). Population Monograph of Nepal. Kathmandu: Author.

International Monetary Fund. (2003). Nepal: Poverty Reduction Strategy Paper. Washington D.C.: Author.

King, E.M. \& Bellew, R. (1991). Gains in the education of Peruvian women, 1940 to 1980. In B. K. Herz \& S. R. Khandker, Women's Work, Education, and Family Welfare in Peru. Discussion Paper, 116, The World Bank, Washington, DC.

Kambhapati, S., \& Pal, S. (2001). Role of parental literacy in explaining gender difference: Evidence from child schooling in India. European Journal of

Levy, C. (1996). The Process of Institutionalising Gender in Policy and Planning: The Web of Institutionalization. Working Paper, 74. London: University College.

Lillard, L. A. \& Willis, R. J. (1994). 
Schooling: Knowledge, Perception and Practices of Parents $\mid 51$

Intergenerational Educational Mobility: Prennushi, G.(1998). Nepal: Poverty at the Turn Effects of Family and State in Malaysia. $\quad$ of Twenty -First Century. Report, IDP Development Research, 13, 97-119. Journal of Human Resources 29(4),11261166.

Parajuli, M. (2002). Dilemmas and Crisis in Education in Nepa". Unpublished Doctoral thesis submitted to Department of Education Anthropology, The Danish University of Education, Denmark.

Popkewitz, T. S. \& Brennan, M. (1998). Foucault's challenge: Discourse, knowledge, and power in education. British Columbia: Teachers College Press. 174.

NPC/UNICEF. (1992). Children and Women of Nepal: A Situation Analysis. Kathmandu: Author.

Thomas, A. S. (1986). Taiwanese schools against themselves: School sulture verses the subjectivity of youth. In Levinson, A. B, Foley, D.E. \& Holland, D.C. The Cultural Production of the Educated Person Critical Ethnographies of Schooling and Local Practices. New York: State University of New York.

Parker, S. W. \& Pederzini, C.( 2000) . Gender Differences in Education in Mexico. New York The World Bank.

UNESCO. (2004). EFA Global Monitoring Report 2004: Education for All: The Quality Imperative. Paris: UNESCO.

Journal of Education and Research Vol. 2, 2010 